\title{
Inseguridad en América Latina: desigualdad $y$ desarrollo
}

\author{
José Déniz Espinós* \\ Las desigualdades generan inseguridades que impactan negativamente en el desarrollo \\ de un país o región. Además incide el peso de la economía del narco y la captación \\ de personas dispuestas a participar en sus redes. La inseguridad se aprecia en las tasas \\ de homicidios y otros delitos. No obstante la integridad física y material es un derecho \\ humano fundamental y base de la convivencia en sociedad, una función que le corresponde \\ al Estado. Cuando éste no es capaz de garantizarlo se debilita su legitimidad. La seguridad \\ ciudadana implica inclusión y la inseguridad exclusión. La reducción de la violencia \\ delictiva está asociada con formas democráticas de convivencia y participación, \\ lo que fomenta una mayor confianza entre los ciudadanos y entre éstos y las autoridades.
}

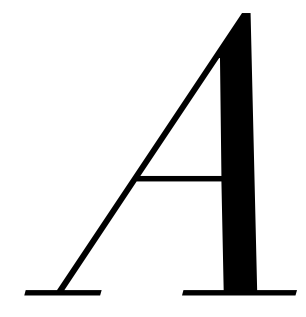

PRIMERA VISTA se hace evidente la relación entre inseguridad, desigualdad y desarrollo, cualquiera sea la conceptualización utilizada. Una posible hipótesis de trabajo podría ser que las desigualdades generan inseguridades que, a su vez, impactan negativamente en el desarrollo de un país o región, en nuestro caso en América Latina y el Caribe. Mucho se viene discutiendo sobre cómo unas determinadas políticas fueron incrementando la heterogeneidad y la polarización en las

* Docente-investigador de la Unidad Académica de Estudios del Desarrollo de la Universidad Autónoma de Zacatecas, México. diferentes estructuras nacionales, lo que agudizó las viejas desigualdades o creó nuevas; esto produjo una mayor inseguridad económica (sobre todo por no alcanzar las expectativas creadas por el discurso dominante) que trajo como consecuencia unos mayores grados de violencia. En este contexto es donde habría que añadir el peso de la economía del narco y la captación de personas dispuestas a participar en sus redes.

En un análisis más puntual y delimitado habría que precisar estos factores, dado que las grandes generalizaciones llevan con seguridad a errores de apreciación tanto en el ámbito del diagnóstico como en las respuestas para paliar la afectación de los derechos humanos fundamentales, empezando por la vida. ¿Acaso existe un único contexto y unas únicas políticas 


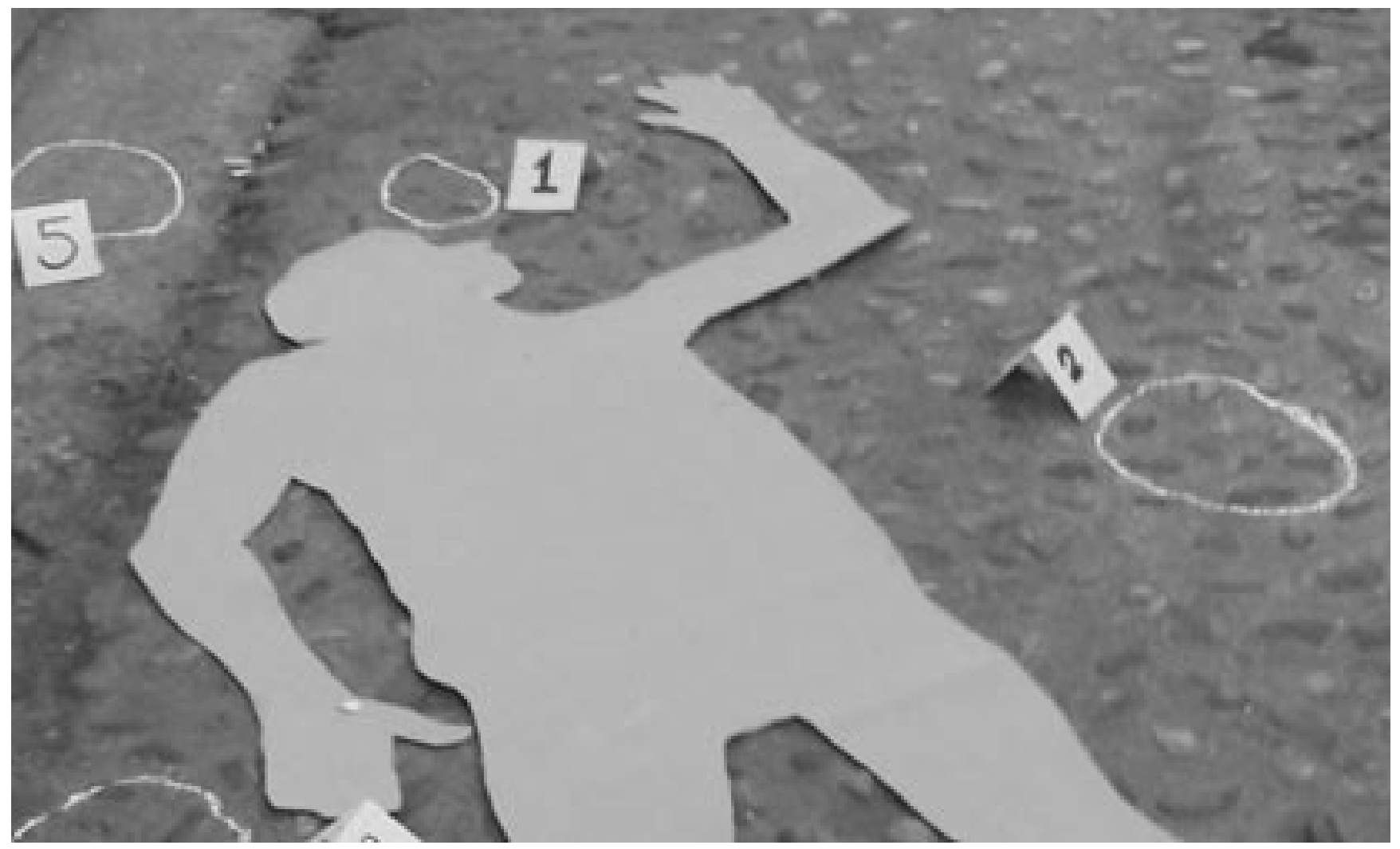

La espiral de violencia asociada a la economía criminal arroja una cifra fúnebre de homicidios semejante a la de países en situación de guerra entre Estados.

aplicadas en el subcontinente? ¿Es cierto que uno u otro, según el que sea, produce más o menos inseguridad y violencia en la sociedad? Cuando se habla de desigualdades, ¿éstas se reducen tan sólo a las de ingreso y riqueza o existen múltiples niveles de desigualdades que inciden de una manera u otra según los países? ¿La inseguridad es sólo física o incluye también la inseguridad económica (desempleo, pobreza y exclusión, por ejemplo) u otras como las que tienen que ver directamente con componentes estructurales tales como la corrupción, la condición de género, etcétera? Además de la violencia física, ¿cómo medir la violencia psíquica, emocional o intelectual? ¿A qué desarrollo se hace referencia cuando no existe una sola concepción de lo que se entiende por ello? ¿Quiénes son los actores sociales e institucionales (públicos y privados) que forman parte de este proceso? ¿Cuál es el papel del Estado, incluyendo el Poder Judicial y los cuerpos de seguridad? ¿Y el papel de los dirigentes empresariales? ¿Cómo influyen los valores éticos y morales dominantes? En fin, como se decía, es necesario precisar y delimitar sobre lo que se analiza, algo que en este caso no ocurrirá, pues tan sólo aquí se dejan señalados algunos aspectos generales que pueden servir para un debate más matizado.
Ante la imposibilidad material de hacer un estudio más en profundidad y de estudios de caso, en este artículo se dejan planteadas algunas consideraciones de alcance necesariamente breve. Así, inicialmente se recogen algunos aspectos y datos sobre la inseguridad en América Latina y el Caribe para después considerar los costos de la inseguridad y la relación existente con el crecimiento económico y el papel del Estado. Posteriormente, se contemplan unas menciones al tema del narcotráfico, las prohibiciones y su implicación en la violencia para, finalmente, exponer unas reflexiones muy generales que hacen hincapié en la utilización del miedo, la seguridad y los negocios por parte de algunos grupos de interés que son protagonistas y beneficiarios de estas circunstancias y ante los cuales se debe estar muy alerta.

\section{Inseguridad en América Latina}

Los indicadores de inseguridad ciudadana abarcan un amplio espectro de hechos de violencia que afectan la integridad física y material de las personas, pero también la psicológica, aunque ésta sea más difícil de registrar y medir. Entre los indicadores están los homicidios, 
robos, hurtos, violaciones, secuestros, etcétera, incluyendo cada vez más la violencia doméstica y el acoso escolar (bullying), tanto infantil como juvenil. Por su parte, los delitos llamados de cuello blanco, como el fraude, la estafa, la corrupción, etcétera, deben considerarse como parte de este marco conceptual, y en algunos países se tiende a legislar para su penalización, sobre todo como resultado de la crisis financiera más reciente que demostró su preeminencia empresarial y política.

La inseguridad reinante se aprecia, por ejemplo, en las tasas de homicidios y otros delitos. Así es como América Latina ha mostrado una tasa de homicidio promedio superior a la de las demás regiones del mundo en los últimos años, específicamente de casi 28 por ıoo mil habitantes en el periodo 2009-20II, siendo este valor más de io veces mayor al promedio de Europa y Estados Unidos en ese mismo periodo, a la vez que esta tasa se ha mantenido relativamente estable en niveles altos en América Latina, mientras que se ha reducido en el resto de las regiones. Con todo, hay que decir que existe mucha heterogeneidad en el interior de la región, donde las disparidades son muy notables (véase más adelante). Asimismo, debe resaltarse que, dependiendo de las fuentes, las tasas varían significativamente y que hay ausencia de estadísticas confiables, sobre todo cuando las de origen nacional son muy inferiores respecto a las de organismos internacionales.

Más allá de los homicidios, la incidencia de otros delitos como los asaltos, hurtos y robos también es alta en la región. En particular, los asaltos (crímenes de contacto) son 3.5 veces más frecuentes en la región que en Europa (52I frente a I5o por cada Ioo mil habitantes), aunque estas comparaciones deben tomarse con mucha cautela debido a posibles diferencias en las definiciones y sistemas de registro de cada delito por país. Para una mejor caracterización deben recordarse las siguientes conceptualizaciones: el hurto es "el delito que consiste en tomar o retener bienes ajenos contra la voluntad de su dueño, sin intimidación en las personas ni fuerza en las cosas"; el robo se define como "la apropiación de algo ajeno con violencia o fuerza"; y el asalto es "apoderarse de algo por la fuerza, con las armas y por sorpresa".

El panorama que se describe es tan grave que la Corporación Andina de Fomento (CAF)' dice que la región "atraviesa una crisis de proporciones epidémicas en la protección y garantía de sus derechos humanos fundamentales". Unas estadísticas lo ilustran:
El número de homicidios por cada ıoo mil habitantes se duplicó en los últimos io o I5̆ años en países como El Salvador (35 en 200I-2003 versus 69 en 2009-20II), Venezuela (20 en 1995-1997 versus 5o en 2009-20п) y México 49 en 200I-2003 contra i8 en 2009-20II). También hubo un aumento notable en países con niveles tradicionalmente bajos de delincuencia como Costa Rica, donde la tasa de homicidios pasó de 5 a II muertes por cada roo mil habitantes, o Panamá, donde pasó de io a 2г. Por otro lado, otros países con niveles tradicionalmente altos de crimen, como Colombia y Brasil, han experimentado reducciones importantes de la violencia letal (de 70 a 35 y de 3 o a 2I, respectivamente); sin embargo ésta sigue siendo muy elevada en comparación con la de países desarrollados (menos de 3 homicidios por cada roo mil habitantes) y la de otras regiones en desarrollo como es el sudeste asiático, donde la tasa es 7 .

Por su parte, el Instituto Igarapé (ong de Brasil)² dice que América Latina y el Caribe concentran la tercera parte de los cerca de 450,000 homicidios registrados al año en el mundo, lo que permite concluir que la región "vive una epidemia de homicidios", y mientras que en otras regiones del mundo los homicidios se reducen, en América Latina aumentan. "Con sólo el 8 por ciento de la población mundial, América Latina y el Caribe concentran el 33 por ciento de los homicidios en los 2r9 países analizados. Se trata de un número muy alto". Mientras que el índice mundial de homicidios al año es de 6.2 por cada ıoo,ooo habitantes, en gran parte de los países latinoamericanos y caribeños esa tasa es de más de 20 por cada Ioo,ooo habitantes.

De los 20 países con mayores tasas de homicidio, I6 son de América Latina. La lista la encabezan: Honduras con 85.52 homicidios por cada Ioo,ooo habitantes, Venezuela (53.7), Islas Vírgenes (52.6o), Belice (44.74) y Jamaica (40.59). El Salvador es el séptimo de la lista con 35.7 I homicidios por Ioo,ooo habitantes, Guatemala está en noveno lugar (34.74), Colombia en undécimo (33.76), Brasil en decimoquinto (29.0o), Puerto Rico en decimoctavo (27.67) y República Dominicana en vigésimo (34.42). Brasil, sin embargo, es el primer país del mundo en números absolutos de homicidios, con 56,337 en 2012, seguido por India (43,355), Nigeria $(33,8$ I 7$)$ y México $(25,967)$.Venezuela es séptima en esta lista con 16,072 homicidios, y Colombia ocupa noveno lugar (I/4,294).

Por su parte, Joaquín Villalobos (exguerrillero salvadoreño y consultor para la resolución de conflictos internacionales ${ }^{4}$ hace notar que "en lugares de Asia 


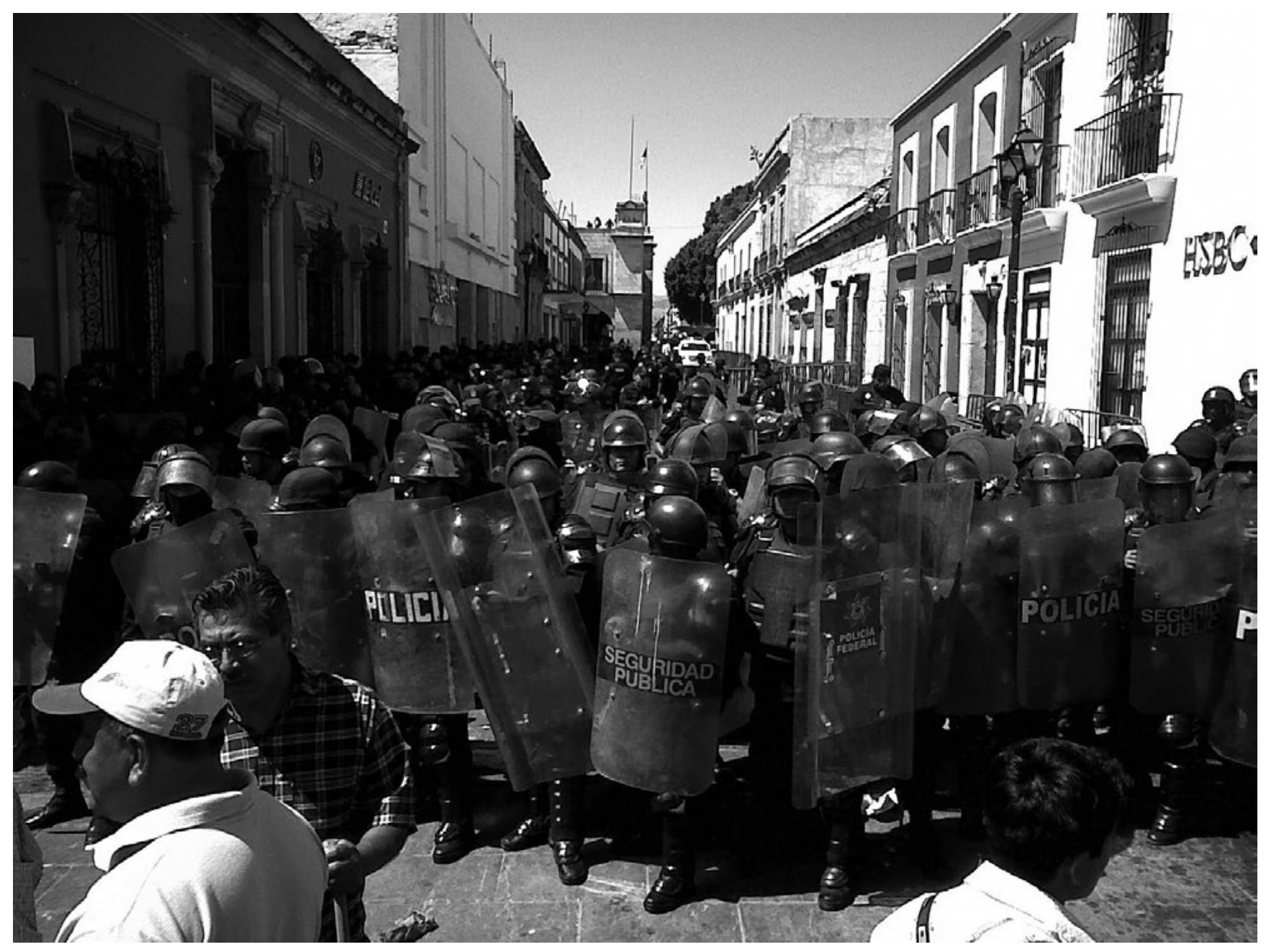

El Estado despliega fuerzas del orden para disuadir, contener o reprimir a los movimientos sociales.

donde domina el Estado Islámico, la blasfemia, el adulterio, la herejía y el 'espionaje' de los 'infieles' se pagan con la muerte", mientras que en lugares de Latinoamérica dominados por delincuentes, los que no pagan extorsiones, las mujeres que se resisten a ser violadas y aquellos que conversan con policías o rechazan colaborar con los criminales son asesinados". Por su parte, mientras que "el terrorismo islámico decapita y crucifica en sus territorios, en Latinoamérica los criminales cuelgan, decapitan, queman, descuartizan y juegan fútbol con las cabezas de las víctimas. En ambos casos el terrorismo es el método para tener autoridad". Recordando que mientras en estos momentos en Asia, África y Europa del Este hay i5 guerras por distintos motivos, "Latinoamérica es una región sin guerras, con grandes progresos democráticos, económicos y sociales y en la cual decenas de millones de personas han salido de la pobreza. Sin embargo, es la región más violenta del mundo, 3oo homicidios por día, ıoo,ooo por año y más de un millón y medio en los últimos I4 años".
Lo cierto es que, más allá de estos datos, la percepción de inseguridad es muy alta entre la población latinoamericana, según se recoge en distintas fuentes. Actualmente, casi 30 por ciento de los habitantes de la región considera que la inseguridad es el principal problema que afecta su bienestar, por encima del desempleo, la inflación o la provisión de bienes públicos básicos como salud o educación; ${ }^{5}$ y 60 por ciento de la población de las principales ciudades de América Latina piensa que la inseguridad se ha incrementado en los últimos 5 años. ${ }^{6}$ No debe olvidarse que la inseguridad en muchos casos es una violación a la vida y siempre es una restricción a la libertad, empezando por la de circulación, que aflige particularmente a los sectores populares de la sociedad, lo cual agrava las condiciones de desigualdad en las que están. A ellos hay que añadir, cada vez más, otros sectores de la población que tienen más altos ingresos, como son las capas medias. Los de ingresos superiores recurren a mecanismos de protección privada, lo que les permite minimizar los 
efectos negativos. Por lo tanto, la inseguridad tiene costos directos, tanto por el lado de los actos delictivos como del lado de la respuesta, influyendo negativamente en las decisiones económicas, comprometiendo de esta manera posibilidades de crecimiento y, sobre todo, de desarrollo.

En sus programas de desarrollo, la Organización de las Naciones Unidas (ONU) ha reconocido la integridad física y material como un derecho humano fundamental, por ser la base más elemental para sostener la convivencia en sociedad, función que le corresponde al Estado. Cuando éste no es capaz de garantizar este derecho a todos los habitantes se debilita su legitimidad como garante del contrato social. En esta medida, la seguridad ciudadana implica inclusión y la inseguridad exclusión. La reducción de la violencia delictiva está asociada con formas democráticas de convivencia y participación, lo que fomenta una mayor confianza entre los ciudadanos y entre éstos y las autoridades. Por eso es necesario poner el mayor y estratégico énfasis en la seguridad ciudadana, dado que la seguridad pública pone el énfasis en los poderes coercitivos del Estado que, por más legales y legítimos que puedan ser, no dejan de basarse en la represión para combatir el delito, algo que a corto plazo seguramente es imprescindible, pero que combate tan sólo las consecuencias y no las causas y su significado.

\section{Costos de LA INSEGURIDAD,} CRECimiento ECONómico y PAPEL del Estado

Como se dijo antes, el crimen y la violencia tienen altos costos para la sociedad y éstos no son sólo directos sino también indirectos. Entre otros, los costos directos incluirían una menor esperanza de vida y otras consecuencias negativas del delito sobre la salud física y psicológica de las personas afectadas; los gastos públicos y privados asociados a la prevención y el control del delito (p. ej., la policía), el sistema de justicia penal y las cárceles; y los bienes y las propiedades perdidas o destruidas a causa del crimen. Los costos indirectos se verifican en los cambios de conducta que adoptan las personas para evitar el delito (p. ej., menos actividades recreativas o fuera del hogar); los efectos sobre las decisiones de participación laboral e inversión en capital humano de las familias y las decisiones de inversión y producción de las empresas; y el impacto sobre la confianza entre los ciudadanos y por parte de los ciudadanos en el gobierno y las instituciones.
Dada la multiplicidad de canales a través de los cuales el delito y la violencia afectan el bienestar, las consecuencias sobre el potencial de desarrollo de un país son muy difíciles de cuantificar, aunque se han elaborado algunos métodos para estimarlos a pesar de que pueden llevar a errores. A título informativo, y tan sólo para dar cierta idea de la complejidad, se recuerda que algunos suman los gastos directos (públicos y privados) en salud y en prevención y control del delito, y que se realizan como consecuencia del crimen; el valor de la propiedad destruida como consecuencia del crimen; y los salarios perdidos por los individuos encarcelados o de las personas incapacitadas o fallecidas como consecuencia del crimen. La información para estas estimaciones suele provenir de fuentes secundarias que incluyen el presupuesto público, la encuesta de gasto de hogares, los registros médicos con detalle de gastos por tipo de lesiones, la información censal con datos demográficos de víctimas y criminales, y las decisiones judiciales sobre las compensaciones otorgadas a las víctimas.

Con estas prevenciones, y sólo con la voluntad de ilustrar lo que se está comentando, autores como Londoño y Guerrero ${ }^{7}$ proveen estimaciones de este tipo para América Latina, que se hicieron hace años, basadas en estudios de caso para cinco ciudades de la región (Caracas, Cali, El Salvador, Lima, México Distrito Federal y Río de Janeiro). Los autores estiman que el crimen implica un costo total de aproximadamente 5 por ciento del producto interno bruto (PIB) en América Latina: 2 por ciento por concepto de atención médica y años de vida perdidos y 3 por ciento por concepto de gastos de seguridad (pública y privada) y justicia. Como punto de comparación, un autor como Soares ${ }^{8}$ estima el costo total del crimen en Estados Unidos en 4 por ciento del PIB. La encuesta CAF 2013 provee información más micro sobre el costo del crimen: 24 por ciento de los encuestados menciona haber instalado cerraduras de seguridad y rejas; I7 por ciento dice tener perros de vigilancia y I2 por ciento menciona haber recurrido a cámaras, vigilancia privada o alarmas. Todo con un costo para los hogares de 4 por ciento de su ingreso. Además, los encuestados estiman el valor de los bienes perdidos y el de otros gastos incurridos para reparar el daño relacionado en 6 por ciento del ingreso anual de sus hogares.

La dificultad de estimar los costos de las diferentes modalidades de delincuencia puede llevar a plantear hipótesis que se enfrentan a un verdadero problema 


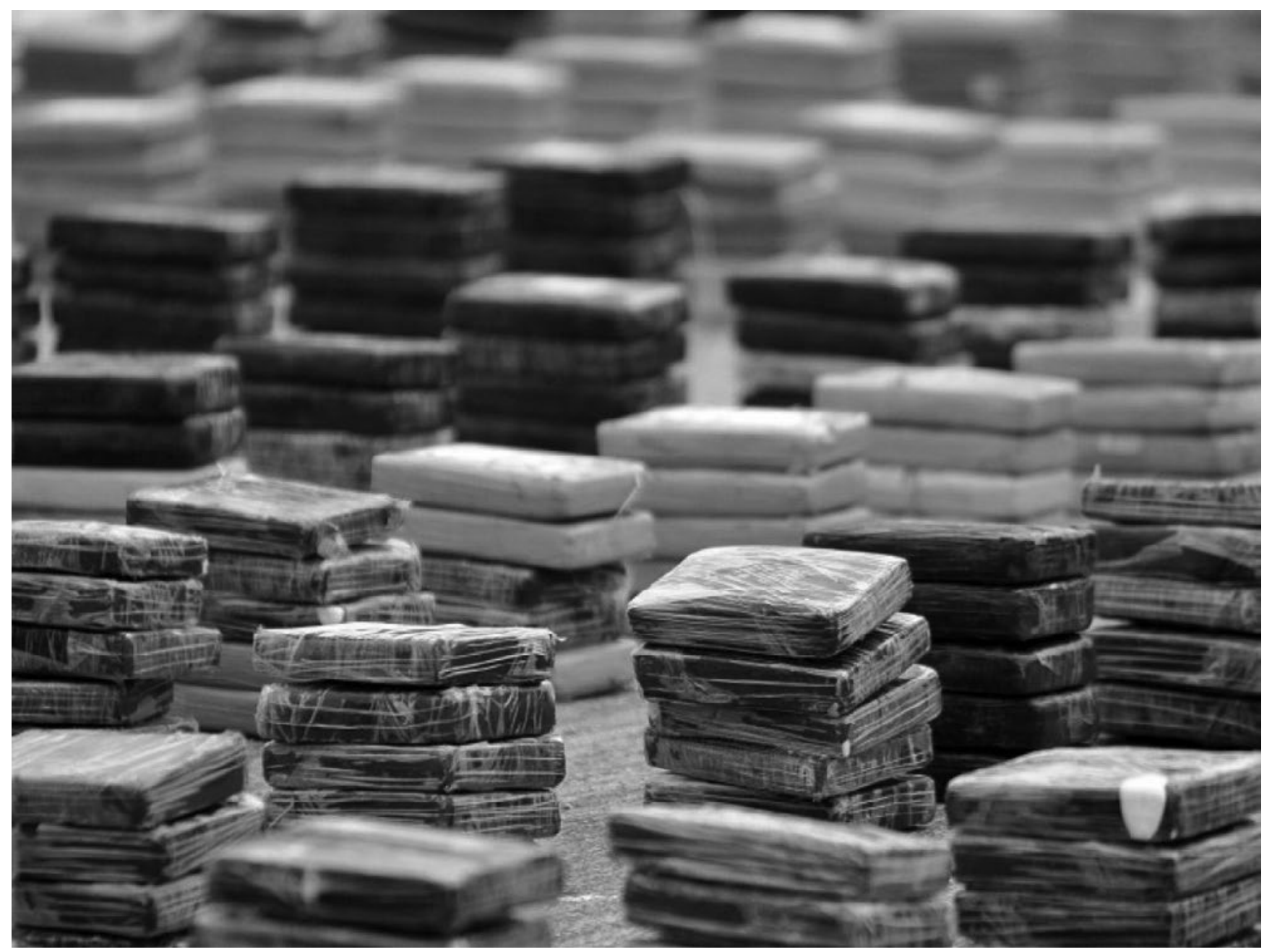

Las drogas alcanzan elevadas cotizaciones en el mercado negro que reporta fabulosas ganancias

a los grupos criminales y al sector financiero coludido.

de identificación, como que "más crimen puede generar menos inversión y empleo" o que "menos inversión y empleo pueden generar más crimen”, por lo que es necesario tener bien establecidas las variables en consideración y su relación. En cualquier caso, la opinión generalizada en las instituciones formales es que el crimen y la violencia generan costos económicos y sociales significativos para las sociedades, dado que tienen consecuencias negativas sobre la participación laboral, los salarios y las decisiones de inversión de las empresas. La frase más utilizada es que "la falta de seguridad pública dificulta el crecimiento económico", pues la ausencia o disminución de la confianza, sobre todo en el ámbito internacional, inhibe la asignación eficiente de recursos en la economía, por lo que es crucial la fortaleza de las instituciones y del Estado de derecho.

Por ello es muy relevante considerar la legitimidad del Estado y las capacidades institucionales. La seguridad ciudadana es fundamental para el bienestar de las comunidades y de los hogares, por lo que el incremento del delito y de la violencia en los países de la región, con altos costos sociales y económicos, compromete la gobernabilidad democrática y la legitimidad del Estado, porque ha socavado la confianza ciudadana. Un Estado incapaz de proveer seguridad de manera adecuada trajo como resultado el intentar hacer justicia por mano propia, favoreciendo además el uso excesivo de la fuerza, minando la legitimidad en sus formas y contenidos, sobre todo los que corresponden a sus manifestaciones democráticas, esto ha complejizado aún más la situación. Las necesarias capacidades institucionales de los gobiernos, como dice el CAF, 9 "no aparecen en el vacío sino de la conjunción de decisiones políticas de priorizar estos temas, la cual, a su vez, depende de que los ciudadanos - a través de su voto y participación - presionen a sus representantes". Pero además, lo que es de enorme alcance, "se requiere de burocracias públicas debidamente entrenadas y con incentivos y recursos para la acción efectiva". 
Narcotráfico, Prohibición y Violencia

Un punto aparte en la temática de la inseguridad, el delito y la violencia, el menoscabo del Estado, la convivencia social y las actividades económicas es el que concierne a la prohibición de la producción, comercialización y consumo de un producto /dimensiones duramente económicas y financieras, además de empresariales), puesto que trae consecuencias significativas sobre el tipo de interacción que las personas pueden tener en torno a ello. Esto suele ocurrir con cualquier producto, sean la caoba o los dvds o, décadas atrás, la venta de bebidas alcohólicas; pero el caso más notorio en América Latina hoy es el de las drogas, cuyo impacto como generador de violencia y de corrupción ha superado con creces a cualquier otro producto, a tal grado que cuestiona los cimientos del sistema vigente y de sus principales dirigentes.

La ilegalidad de ciertos mercados tiene, en muchos casos, relación con la seguridad ciudadana, porque la violencia física suele ser un recurso utilizado para resolver conflictos en estos mercados. En los recientes años, el caso de Colombia ha sido la experiencia más citada, al punto de convertirse en un obligado referente. En este país se estima que entre 1994 y 2008 el 25 por ciento de los homicidios fueron consecuencia del narcotráfico. La extrema violencia se fue convirtiendo en una constante, añadiéndose más recientemente a este caso determinados territorios de Centroamérica y de México, con cifras muy altas de muertes, desaparecidos, heridos y otros graves efectos. Naturalmente que no se puede omitir su incidencia en la salud de los consumidores y en el entorno social, incluida la que corresponde a los nacionales. Por ello, se hace obligatorio tomar en consideración la estructura integral del problema, pues la valoración parcial no hace más que entorpecer la solución.

Lo que debe siempre tenerse presente en el análisis es que para que un mercado ilegal genere violencia hace falta que genere renta económica. A mayores rentas generadas por el producto las posibilidades de disputas por el control de los mercados serán mayores, sea en la esfera de la producción, el transporte o la comercialización. Esas disputas se resuelven recurriendo a la violencia, no sólo porque la tasa de ganancia es muy elevada, sino porque no existen otras instancias formales para resolverlas, dada la naturaleza ilegal de la actividad. De esta constatación se deriva la necesidad de disminuir las rentas, sea porque las barreras de entrada disminuyen o desaparecen o por la caída de la demanda. Lo inevita- ble es atacar el problema dándole una alta prioridad a los factores económicos y financieros, pues los aspectos jurídicos, sanitarios y éticos, sin disminuir su relevancia, no son nada suficientes. Los grupos de poder que están en juego son muy poderosos y no renunciarán fácilmente a un negocio altamente rentable, por lo que el desafío ante el que se encuentran el Estado y la sociedad es muy alto y riesgoso.

Con todo acierto, Villalobos ${ }^{10}$ recordaba hace poco tiempo que "Latinoamérica tiene sociedades nuevas gobernadas por instituciones viejas", lo que incluye a las instituciones de seguridad, en un contexto que caracteriza de "crisis de una ciudadanía inhibida por un Estado débil, un Estado ausente o un Estado cooptado por criminales". En otro momento recuerda que "existen territorios urbanos o rurales donde el Estado ha perdido o está perdiendo los monopolios de la fuerza, la tributación y la justicia a manos de criminales". Está claro que la crisis del Estado es un elemento que explica la inseguridad y la violencia, donde "los vacíos de autoridad que ya existían o que dejó el periodo autoritario fueron ocupados por delincuentes y no han podido ser llenados por la autoridad democrática", perdiendo así el Estado una de sus primeras responsabilidades con los ciudadanos, como es la seguridad.

Partiendo de su experiencia, incluyendo el caso de Colombia, el consultor Villalobos propone cuatro ejes estratégicos que permitirían "derrotar al crimen": a) la reforma de las instituciones de seguridad, teniendo a los derechos humanos como pilar de la legitimidad del Estado; b) el incremento sustancial de la fuerza del poder coercitivo; c) la participación de los ciudadanos; y d) la presencia integral del Estado en el territorio. Con la defensa de los derechos humanos se obtiene una "ventaja moral", una alta densidad policial permanente y especializada disuade el delito, como asimismo ocurre con la participación ciudadana y con la presencia estatal. Sin embargo, es inequívoco que el poder coercitivo a mediano plazo no es suficiente, sino que es fundamental la acción de las instituciones públicas encargadas de ofrecer "servicios de salud, justicia, deporte, educación, cultura, agua, transporte y entretenimiento a los ciudadanos". Junto a ello hay que potenciar la economía local, puesto que el empleo es estratégico para la política de desarrollo que se implemente. Asimismo, es indispensable una mejor selección del personal policial, con una mejor formación técnica y moral y una mejor retribución económica, además de unos jefes acordes a esos requerimientos. 
Reflexiones finales (MIEDO, SEGURIDAD Y NEGOCIOS)

Dicho todo lo anterior, no se puede omitir decir que hay que estar muy atentos a que no se nos regale ahora el miedo y la paranoia para vendernos seguridad, para hacer después "negocio" de ese miedo y de esa paranoia que trata de infundirse.

Cuando el miedo cala en determinados sectores sociales éstos buscan la seguridad a cualquier precio, sacrificando así cualquier otro bien social (colectivo), incluyendo la libertad, lo que suele llevar a formas de control autoritarias que las nuevas tecnologías facilitan y que hacen innecesario recurrir a métodos tradicionales de violencia física. Y todo ello en nombre de la seguridad y la paz.

Los tiempos de crisis son muy propicios a estas modalidades de reducción de derechos adquiridos, de logros alcanzados en el proceso de conquista del bienestar integral que busca la inmensa mayoría de los ciudadanos de América Latina y del mundo.

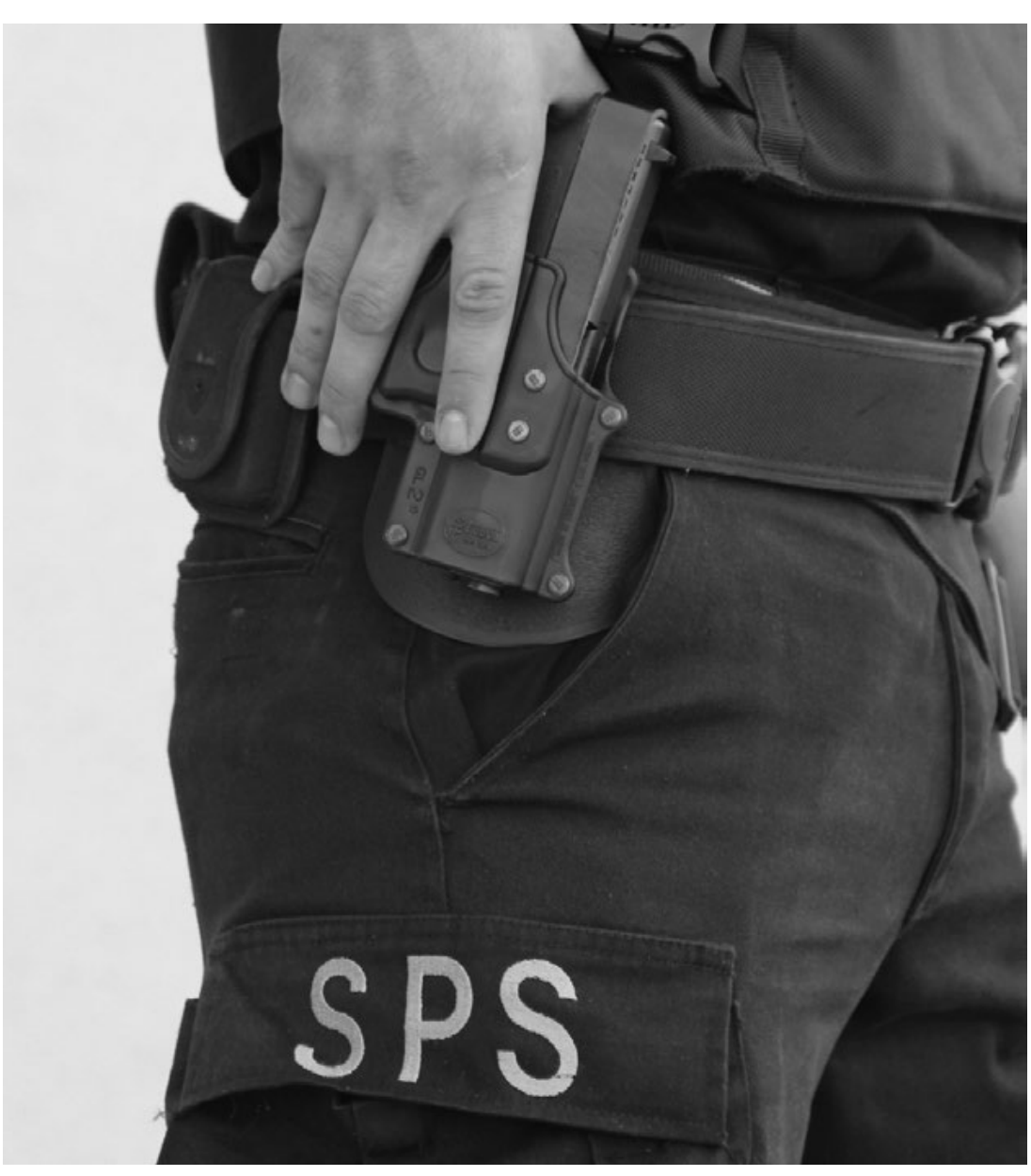
grados importantes de autonomía. Son considerados como los nuevos mercenarios globalizados. Sin duda que esto está cambiando el orden mundial y sus reglas, sustituyendo el papel de los viejos Estados. Esta última situación hay que relacionarla con la industria militar, predominantemente en manos de grandes grupos empresariales y con altas tasas de ganancia con efectos favorables en el PIB de una economía.

En definitiva, es altamente probable que una sociedad que tenga unas políticas de desarrollo, que intente conseguir menos desigualdades y más justicia, más empleo digno y mejor retribuido, en donde todos los niños y jóvenes estudien, que tenga servicios públicos eficientes y transparentes en sus finanzas, una sustentabilidad ambiental y territorial y unos valores éticos basados en la solidaridad, entre otras cosas, podría ser menos insegura y seguramente más feliz. 
Corporación Andina de Fomento (CAF) (20I4), Por una América Latina más segura. Una nueva perspectiva para prevenir y controlar el delito, Banco de Desarrollo de América Latina, Corporación Andina de Fomento, Bogotá, junio, p. I9.

${ }^{2}$ Efe, io de mayo de 2015 .

${ }^{3}$ Renata Giannini, coordinadora del proyecto.

${ }^{4}$ El País, 7 de mayo de 2015.

${ }^{5}$ Latinobarómetro, $201 \mathrm{II}$.

${ }^{6}$ Encuesta CAF 2013.

7 J. L. Londoño y R. Guerrero (2000), "Violencia en América Latina: epidemiología y costos”, en J. L. Londoño, A. Gaviria y R. Guerrero (eds.), Asalto al desarrollo: violencia en América
Latina Washington D.C., Banco Interamericano de Desarrollo, pp. II- 57 .

${ }^{8}$ R. R. Soares (2010), Welfare Costs of Crime and Common Violence: A Critical Review (Documento para la Discusión, num. 58I), Río de Janeiro, Pontifícia Universidade Católica do Rio de Janeiro.

9 Corporación Andina de Fomento (CAF) (2014), Por una América Latina más segura. Una nueva perspectiva para prevenir y controlar el delito, Banco de Desarrollo de América Latina, Corporación Andina de Fomento, Bogotá, junio, p. 47.

'o Joaquín Villalobos (2015), "Un millón y medio de muertos", El País, Madrid, 7 de mayo.

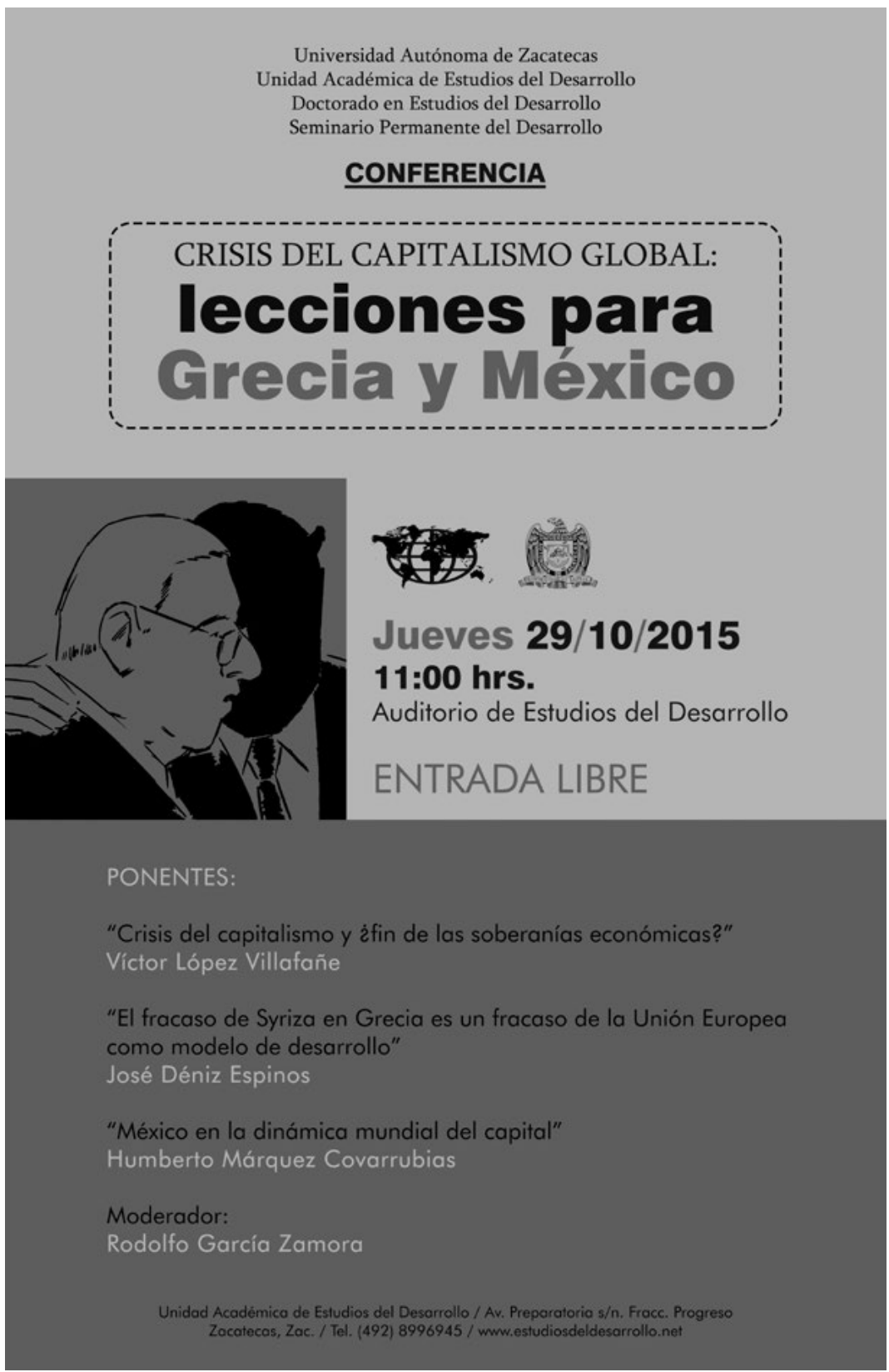

